\title{
Effect of high-pressure homogenization on droplet size distribution and rheological properties of ice cream mixes
}

\author{
N. Innocente, ${ }^{1}$ M. Biasutti, E. Venir, M. Spaziani, and G. Marchesini \\ Department of Food Science, Faculty of Agriculture, University of Udine, Udine, Italy
}

\begin{abstract}
The effect of different homogenization pressures $(15 / 3$ $\mathrm{MPa}$ and $97 / 3 \mathrm{MPa}$ ) on fat globule size and distribution as well as on structure-property relationships of ice cream mixes was investigated. Dynamic light scattering, steady shear, and dynamic rheological analyses were performed on mixes with different fat contents (5 and 8\%) and different aging times (4 and $20 \mathrm{~h}$ ). The homogenization of ice cream mixes determined a change from bimodal to monomodal particle size distributions and a reduction in the mean particle diameter. Mean fat globule diameters were reduced at higher pressure, but the homogenization effect on size reduction was less marked with the highest fat content. The rheological behavior of mixes was influenced by both the dispersed and the continuous phases. Higher fat contents caused greater viscosity and dynamic moduli. The lower homogenization pressure $(15 / 3 \mathrm{MPa})$ mainly affected the dispersed phase and resulted in a more pronounced viscosity reduction in the higher fat content mixes. High-pressure homogenization (97/3 MPa) greatly enhanced the viscoelastic properties and the apparent viscosity. Rheological results indicated that unhomogenized and $15 / 3 \mathrm{MPa}$ homogenized mixes behaved as weak gels. The $97 / 3 \mathrm{MPa}$ treatment led to stronger gels, perhaps as the overall result of a network rearrangement or interpenetrating network formation, and the fat globules were found to behave as interactive fillers. High-pressure homogenization determined the apparent viscosity of $5 \%$ fat to be comparable to that of $8 \%$ fat unhomogenized mix.
\end{abstract}

Key words: ice cream mix, high-pressure homogenization, particle size distribution, rheology

\section{INTRODUCTION}

Homogenization is widely employed in the food industry for emulsion stabilization and to improve the texture, taste, and flavor of many products including

Received October 9, 2008.

Accepted December 16, 2008.

${ }^{1}$ Corresponding author: nadia.innocente@uniud.it milk, milk cream, and ice cream mixes. Homogenization leads to a reduction in size and an increase in number of solid or liquid particles of the dispersed phase. During this process, the fluid is subjected to several simultaneous force-induced phenomena such as cavitation, turbulence, shear, friction, heat, compression, acceleration, rapid pressure drop, and impact (Phipps, 1975; Fellows, 1988; Paquin, 1999; Floury et al., 2000; Roach and Harte, 2008). All these forces are significantly increased as pressure increases. For this reason, homogenization technology has evolved from systems operating at less than $50 \mathrm{MPa}$ (conventional pressure, CP) to devices working at up to $200 \mathrm{MPa}$ [high pressure (HP) and ultra-high-pressure homogenization (UHP); Floury et al., 2000, 2002, 2003; Desrumaux and Marcand, 2002; Sandra and Dalgleish, 2005; Bouaouina et al., 2006; Roach and Harte, 2008].

The forces involved in HP homogenization may produce different effects on food macromolecules (fat, proteins, and polysaccharides). With regard to fat, the homogenization process results in smaller fat globules and a more uniform size distribution, thus limiting the rate of phase separation. The mean fat drop size $(d)$ is reduced, with increasing pressures $(P)$, following the exponential relationship $d \propto P^{-m}$, with $m$ related to the applied pressure and the fat content of the system (Phipps, 1975; Kessler, 1981; Floury et al., 2000, 2003; Desrumaux and Marcand, 2002). The value of $m$ has been reported as equal to 0.6 in emulsions with a low dispersed phase fraction, whereas it decreases at higher fat contents (Floury et al., 2000).

With reference to milk proteins, there are few works in the literature on dynamic HP homogenization effects. In oil emulsions, no change has been observed in the primary and secondary structure of $\beta-\mathrm{LG}$ and $\alpha$-LA after HP treatment $>200 \mathrm{MPa}$ (Subirade et al., 1998; Paquin, 1999; Desrumaux and Marcand, 2002). Nevertheless, it has been suggested that the protein architecture is stabilized by slightly different interactions following the treatment (Subirade et al., 1998). In contrast, Bouaouina et al. (2006) did not observe significant changes in the native structure of $\alpha$-LA and $\beta$-LG when they were in solution. In regard to caseins, their micelle sizes have been found to be modified 
through HP homogenization treatment depending on the pressure applied (Hayes and Kelly, 2003; Sandra and Dalgleish, 2005; Roach and Harte, 2008).

With regard to polysaccharides, Paquin (1999) found a decrease in the average molecular weight of xanthan after homogenization because of an irreversible disruption of the biopolymer. A subsequent change in rheological properties was observed. Similarly, HP homogenization treatment significantly reduced the average molecular weight of methylcellulose. The emulsions stabilized by the disrupted molecules were found to lose their shear thinning behavior and to undergo a large decrease in viscosity (Floury et al., 2003).

Ice cream is a multicomponent system in which air bubbles, ice crystals, and fat globules are dispersed in a freeze-concentrated continuous watery phase consisting of sugars and polysaccharides, milk proteins, and salts (Goff, 1997; Muse and Hartel, 2004). Creaminess, texture, and meltdown behavior of ice cream are strongly affected by partial coalescence of the destabilized fat globules occurring during the freezing process (Marshall and Arbuckle, 1996; Goff, 1997; Goff et al., 1999). Fat globule destabilization is promoted by the modification of the membrane, which is broken down by homogenization. A subsequent rearrangement of the fat globule membrane occurs first with the adsorption of milk proteins, which are then partially displaced by the emulsifiers. The new recombined membrane becomes weaker and thus, much less stable to freezing shear forces. This favors a partial coalescence of the destabilized fat globules leading to a network that stabilizes the air bubbles and the foam structure (Marshall and Arbuckle, 1996; Goff, 1997).

Homogenization pressures employed in ice cream mixes generally range between 6 and $20 \mathrm{MPa}$ depending on fat content (Marshall and Arbuckle, 1996); extensive literature is available with regard to these CP (Schmidt and Smith, 1988, 1989; Koxholt et al., 2001; Goff, 2002 among others). High pressure and UHP have been only recently tested on ice cream mixes and very little has been published (Hayes et al., 2003).

Ice cream mixes are hydrocolloidal dispersions in which proteins and polysaccharides are present in concentrations above the phase separation threshold, determining a 2-phase aqueous system, according to the concept of thermodynamic incompatibility (Tolstoguzov, 2003). Gelation of phase-separated systems can lead to gels filled with liquid or gel-like dispersed particles. Gels are multicomponent systems having a substantial liquid phase but exhibiting solid-like behavior. Ice cream mixes may be considered emulsion-filled gels; that is, macromolecular gels containing dispersed fat particles (filler). The latter may exhibit different filler-gel matrix interactions, strongly influencing structure and rheological properties (van Vliet, 1988). No literature is available with regard to the effects of different homogenization pressures on this complex structure.

In regard to structure, some information on the type of interactions between the conformation and functional properties of molecules and biopolymers can be obtained by rheological analysis such as steady shear flow and dynamic tests.

The aim of this study was to investigate the effect of different homogenization pressures on fat globule size and distribution as well as on structure-property relationships of ice cream mixes. For these purposes, dynamic light scattering, steady shear, and dynamic rheological analyses were performed on mixes with different fat contents (5 and 8\%) homogenized at $15 / 3$ $\mathrm{MPa}$ and $97 / 3 \mathrm{MPa}$ and then aged for 4 and $20 \mathrm{~h}$ at $4^{\circ} \mathrm{C}$. Unhomogenized mixes were used as controls.

\section{MATERIALS AND METHODS}

\section{Ingredients and Ice Cream Mix Formulation}

The following ingredients were used to prepare the ice cream mixes: commercial homogenized and pasteurized whole milk and milk cream (35\% fat) and sucrose (all purchased in a local market), maltodextrins (Natural World s.r.l., Ravenna, Italy), 30 dextrose equivalent glucose (Cerestar France, Haubourdin Cedex, France), skim milk powder (Bayerische Milchindustrie, Landshut, Germany), whey protein concentrate (Borculo Domo Ingredients, Zwolle, the Netherlands), carboxymethylcellulose (Comiel s.r.l., Milan, Italy), guar gum (Indian Gum Industries Ltd., Mumbai, India), locust bean gum (LBG Sicilia s.r.l., Ragusa, Italy), and mono- and diglycerides of fatty acids (Natural World s.r.l.). Two formulations were prepared, containing 5 and $8 \%$ fat, respectively. Table 1 reports their overall composition.

\section{Ice Cream Mix Processing}

The dry ingredients were blended together and added to the liquid ingredients (milk and milk cream) at $65^{\circ} \mathrm{C}$. The mix was then pasteurized at $82^{\circ} \mathrm{C}$ for $8 \mathrm{~min}$ and divided into 3 equal portions. One portion was not homogenized $(\mathbf{C O N})$ and the 2 remaining portions were immediately subjected to homogenization in a 2-stage mode homogenizer (Panda 2K, Niro Soavi s.p.a., Parma, Italy). Conventional homogenization (CP) was performed at a primary pressure of $15 \mathrm{MPa}$ and a secondary pressure of $3 \mathrm{MPa}$ with an inlet temperature of 65 to $70^{\circ} \mathrm{C}$. High-pressure homogenization (HP) was conducted at $97 \mathrm{MPa}$ and $3 \mathrm{MPa}$ with an inlet temperature of 45 to $48^{\circ} \mathrm{C}$ (Hayes et al., 2003). The outlet 
Table 1. Composition of 5 and $8 \%$ fat ice cream mixes

\begin{tabular}{lcc}
\hline Item $^{1}$ & $5 \%$ fat & $8 \%$ fat \\
\hline Total sugars (g/100 g of mix) from: & 19.42 & 19.42 \\
Sucrose (\% of total sugars) & 76.34 & 76.34 \\
30 DE glucose (\% of total sugars) & 21.37 & 21.37 \\
Maltodextrins (\% of total sugars) & 2.29 & 2.29 \\
Total NMS (g/100 g of mix) from: & 10.83 & 10.58 \\
Milk (\% of total NMS) & 55.40 & 49.62 \\
SMP (\% of total NMS) & 28.99 & 29.68 \\
WPC (\% of total NMS) & 10.99 & 11.25 \\
Milk cream (\% of total NMS) & 4.62 & 9.45 \\
Total fat (g/100 g of mix) from: & 5.34 & 7.98 \\
Milk cream (\% of total fat) & 54.68 & 73.31 \\
Milk (\% of total fat) & 43.63 & 25.56 \\
WPC (\% of total fat) & 1.50 & 1.00 \\
SMP (\% of total fat) & 1.09 & 0.13 \\
Emulsifiers (g/100 g of mix) & 0.5 & 0.5 \\
Total stabilizers (g/100 g of mix) from: & 0.25 & 0.25 \\
CMC (\% of total stabilizers) & 60 & 60 \\
Guar gum (\% of total stabilizers) & 20 & 20 \\
Locus bean gum (\% of total stabilizers) & 20 & 20 \\
Total solids (g/100 g of mix) & 36.35 & 38.73 \\
\hline${ }^{1}$ DE = dextrose equivalents; NMS = nonfat milk solids; SMP & skim milk powder; WPC $=$ whey protein \\
concentrate; CMC = carboxymethylcellulose. & &
\end{tabular}

temperatures of all samples did not exceed $80^{\circ} \mathrm{C}$. The $\mathrm{CON}, \mathrm{CP}$, and $\mathrm{HP}$ mix samples were cooled to $4^{\circ} \mathrm{C}$ and aged for 4 and $20 \mathrm{~h}$ without stirring.

\section{Particle Size Distribution Analysis}

Particle size distribution of the mix samples was measured by dynamic light scattering, using a Nicomp 380 ZLS analyzer (Particle Sizing System Nicomp, Santa Barbara, CA). All mix samples were diluted 1:1,000 with a dissociation medium (aqueous solution of $1 \%$ wt/vol SDS; Sigma-Aldrich, Steinheim, Germany). The measurement parameters were set at $25^{\circ} \mathrm{C}$ constant temperature, 1.333 refractive index, scattering angle of $90^{\circ}$ for CON and CP mix samples and $170^{\circ}$ for HP samples. Data were integrated over $3 \mathrm{~min}$. For size analysis, the Nicomp volume-weighted distribution was used.

\section{Microstructure}

Magnifications $(1,000 \times)$ of the ice cream mixes were obtained by using an optical microscope (Axiophot, Carl Zeiss, Oberkochen, Germany) at ambient temperature, using differential interference contrast mode. Samples were placed on a glass microscope slide, covered with a glass coverslip, and immediately observed.

\section{Rheological Analysis}

Rheological tests were carried out by means of a controlled stress rheometer (StressTech rheometer, Reologica Instruments $\mathrm{AB}$, Lund, Sweden) at $4.0 \pm 0.2^{\circ} \mathrm{C}$, using a cone-plate sensor geometry (cone angle $4^{\circ}, 40$ $\mathrm{mm}$ diameter). Before analysis, the sample placed in the rheometer cell rested for $5 \mathrm{~min}$ to allow the stress induced during loading to relax.

Steady Shear Flow. Steady shear flow curves were determined at shear rates $(\dot{\gamma})$ ranging from $0.3160 \mathrm{~s}^{-1}$ to $152.5 \mathrm{~s}^{-1}$. The power law equation was applied to samples exhibiting shear thinning and the Herschel Bulkley to samples with yield stress (Stress Tech 2.24 software for Windows, Reologica Instruments AB). Apparent viscosities $\left(\boldsymbol{\eta}_{\text {app }}\right)$ were taken at a shear rate of 20 $\mathrm{s}^{-1}$.

Dynamic Oscillatory Measurements. Linear viscoelastic regions were determined by stress sweeps at a fixed frequency of $1 \mathrm{~Hz}$. Mechanical spectra were performed in the frequency range 0.1 to $10 \mathrm{~Hz}$, at shear stresses within the linear viscoelastic region.

\section{Statistical Analysis}

For each mix sample, at least 3 experiments were independently performed and all analyses were carried out at least 3 times on the samples. Thus, the data shown are the averages of at least 9 values. Student's $t$-test was used to compare 2 means, and one-way ANOVA (F-test) and Tukey's Honestly Significant Difference test were used for multiple comparisons. In both cases, the differences between the means were considered statistically significant for $P$-values $<0.05$. All statistical analyses were conducted using the software Statistical Discovery JMP 3.0 for Windows (SAS Institute Inc., Cary, NC). 


\section{RESULTS AND DISCUSSION}

\section{Particle Size Distribution}

As an example, Figure 1 shows the particle size distributions of the CON, CP, and HP homogenized ice cream mixes. The CON sample showed a bimodal distribution with a main group of particles above 1,000 $\mathrm{nm}$ and a second group at about 100 to $150 \mathrm{~nm}$ (Figure $1 \mathrm{~A})$. Both the CP and HP samples were characterized by monomodal distributions with smaller mean diameters with respect to the main group of CON (Figure $1 \mathrm{~B}, \mathrm{C})$. In the CON mix, the main group is attributed to the fat globules derived from milk and milk cream, whereas, presumably, the second group refers to casein micelles. Indeed, commercial milk homogenization at 20 and $10 \mathrm{MPa}$ followed by UHT treatment leads to a casein micelle diameter of 110 to $270 \mathrm{~nm}$ (García-Risco et al., 2002). Moreover, it has been reported that casein micelles are disaggregated only by homogenization pressures of $100 \mathrm{MPa}$ (Roach and Harte, 2008). The CP treatment of ice cream mixes could allow casein micelles to disaggregate because of the higher viscosity of the mixes with respect to commercial milk and milk cream. In fact, with the increase in medium viscosity, an increase in the resulting pressure has been reported (Phipps, 1975). Moreover, adsorption of caseins to the fat by the new surface area created following $\mathrm{CP}$ and HP may also occur.

As shown in Figure 2, fat globule mean diameter was reduced by homogenization even though the milk and milk cream used as ingredients had already been subjected to industrial homogenization. As noted above for casein micelle disappearance, the conventional homogenization of mixes would cause a further decrease in fat globule size with respect to the CON mixes, because of the higher viscosity of mixes. Moreover, although mean diameter was consistently decreased by CP, HP caused only a small additional decrease. Fat globule size is known to vary as a function of the applied pressure with an exponential relationship (Kessler, 1981; Floury et al., 2000). In most cases, the homogenized mixes with $5 \%$ fat showed smaller globules than the mixes with $8 \%$ fat. Indeed, fat content was found to influence the relationship between mean diameter and homogenization pressure, with a decrease in the absolute value of the exponent for greater fat amounts (Kessler, 1981; Floury et al., 2000). Different aging times did not affect globule size distribution as also observed by Gelin et al. (1994) and Alvarez et al. (2005). Gelin et al. (1994) attributed this lack of difference to the fact that no noticeable destabilization of the fat globule membranes would occur during aging until freezing takes place with the consequent physical changes.
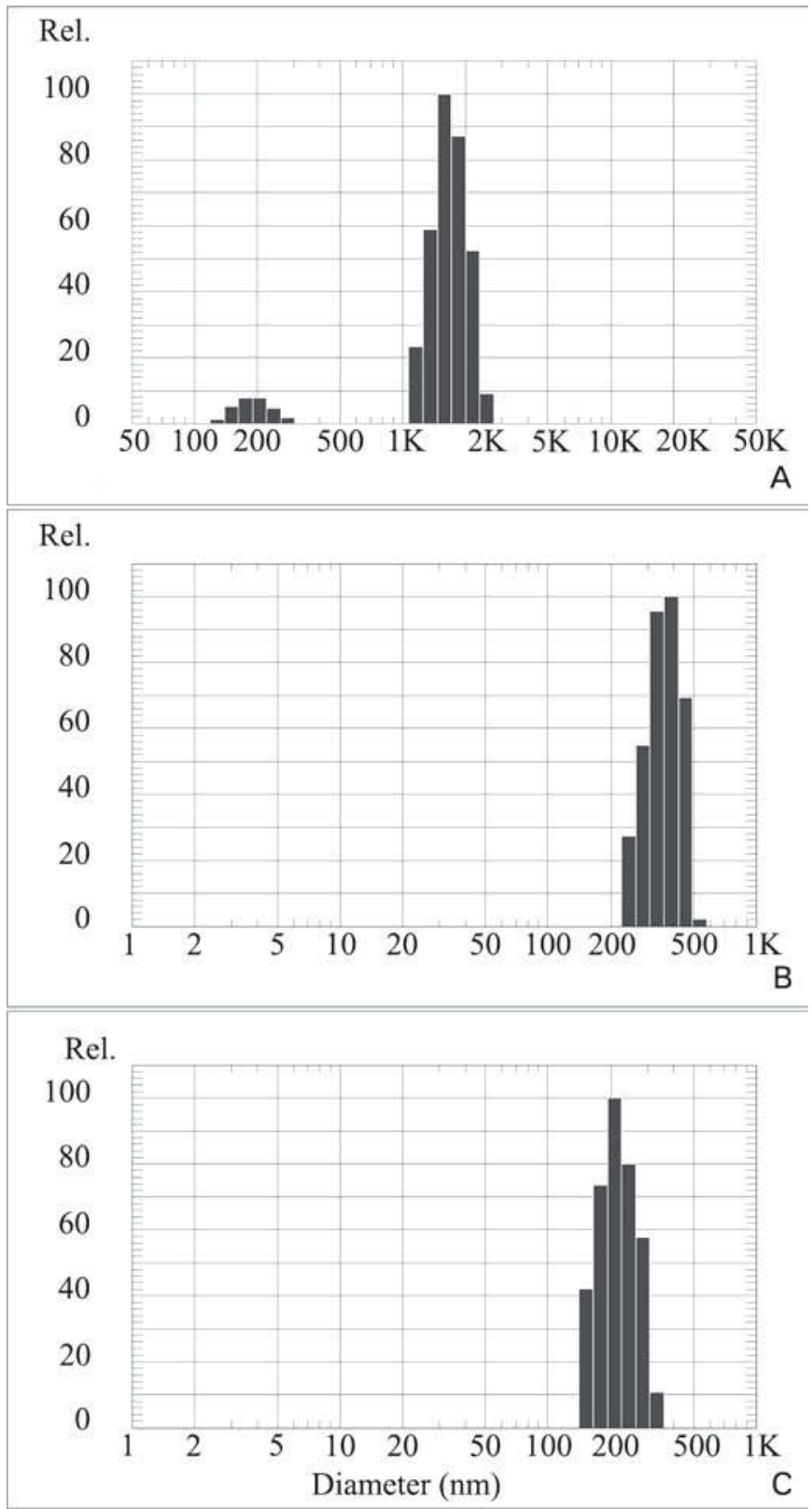

Figure 1. Representative volume-weighted distributions of ice cream mix samples: A) unhomogenized (CON); B) homogenized at 15 and $3 \mathrm{MPa}$ pressure $(\mathrm{CP}) ; \mathrm{C}$ ) homogenized at 97 and $3 \mathrm{MPa}$ pressure (HP).

\section{Microstructure}

Figure 3 shows the microstructures of CON, CP, and HP mixes at 5 and $8 \%$ fat content. Spheroidal elements are fat globules that were smaller in the $\mathrm{CP}$ and $\mathrm{HP}$ samples compared with the CON mix. A further reduction in size was not as evident as it was when observed with dynamic light scattering measurements. The $8 \%$ 

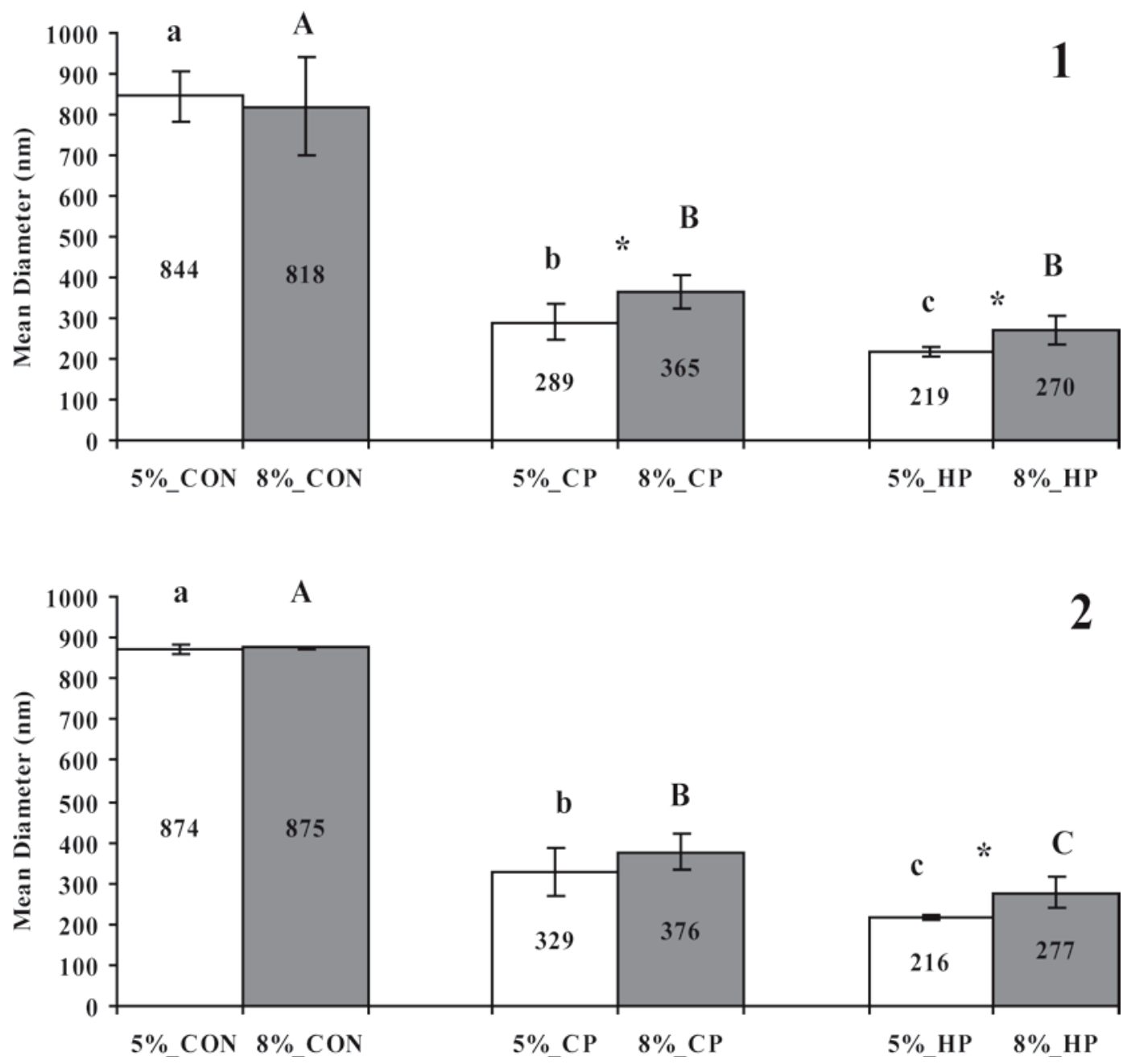

Figure 2. Mean fat globule volume-weighted diameters of ice cream mixes with $5 \%$ and $8 \%$ fat content and aged for $4 \mathrm{~h}$ (panel 1 ) or $20 \mathrm{~h}$ (panel 2). $\mathrm{CON}=$ unhomogenized; $\mathrm{CP}=$ homogenized at 15 and $3 \mathrm{MPa}$ pressure; $\mathrm{HP}=$ homogenized at 97 and $3 \mathrm{MPa}$ pressure. Statistical analysis (Tukey's HSD test, $P<0.05$ ) was carried out within groups at different fat content; lowercase letters refer to $5 \%$ fat content mixes, and uppercase letters refer to $8 \%$ fat content mixes. Asterisks mark statistically different pairs (Student's $t$-test, $P<0.05$ ).

fat HP sample showed a more pronounced 3-dimensional structure.

\section{Steady Shear Flow Behavior}

Steady shear flow determinations allow the shear stress $(\dot{\sigma})$ curves as a function of shear rate $(\dot{\gamma})$ to be determined. Figure 4 shows representative steady shear flow curves of 5 and $8 \%$ fat ice cream mixes aged for 4 and $20 \mathrm{~h}$. All samples were non-Newtonian. The CON and $\mathrm{CP}$ samples were shear-thinning and hence, were described by the power law equation $\left(\mathrm{R}^{2}=1\right)$. The HP sample showed a yield stress, which is the characteristic behavior fitted by the Herschel-Bulkley equation $\left(\mathrm{R}^{2}=\right.$ 0.999). In shear-thinning systems $(\mathrm{n}<1)$, dispersed particles may disaggregate or orient in the direction of flow, opposing less resistance (Lapasin and Pricl, 1995; Aguilera and Stanley, 1999). Both fat globules and stabilizers (locust bean gum and guar gum) may be responsible for the shear-thinning behavior of the mixes (Cottrell et al., 1980; Goff et al., 1994). With regard to HP mixes, the logarithmic plot of shear stress versus shear rate reported in Figure 5 enables the plastic behavior of these samples to be further highlighted (Lapasin and Pricl, 1995). In systems with a yield point, a network structure has to be broken prior to flow. Higher yield stress values marked the $8 \%$ fat mixes (Figure 4 ), indicating more firmly structured systems and, according to Rao (2007), more stable emulsions. In particular, mean yield stress values increased from about $20 \mathrm{~Pa}$ for $5 \%$ fat $\mathrm{HP}$ mixes to about $80 \mathrm{~Pa}$ for $8 \%$ fat HP mixes. In general, the magnitude of the yield stress 

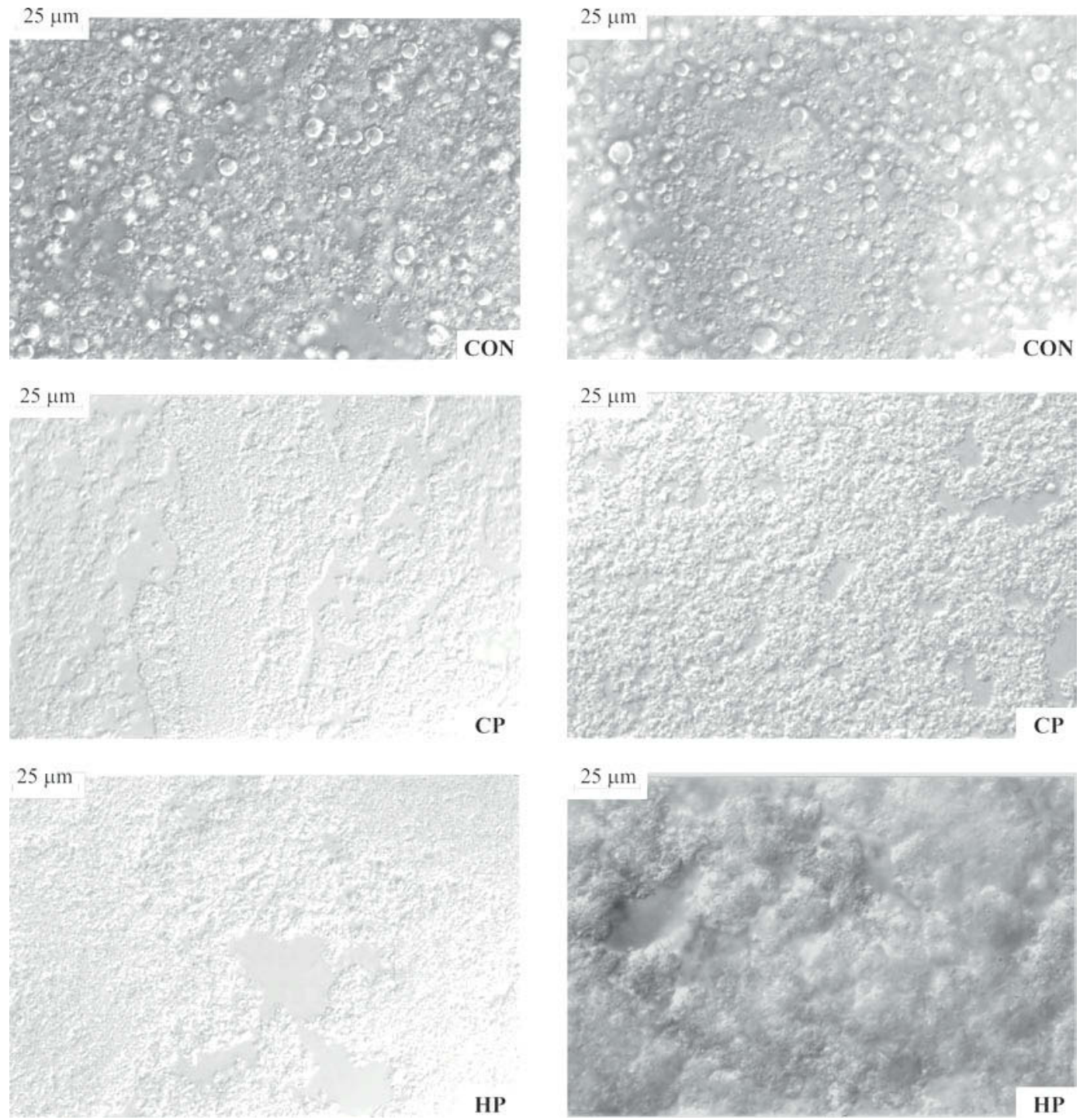

Figure 3. Optical light microscope images of mixes at $5 \%$ (left column) and $8 \%$ (right column) fat content. CON $=$ unhomogenized; CP $=$ homogenized at 15 and $3 \mathrm{MPa}$ pressure; $\mathrm{HP}=$ homogenized at 97 and $3 \mathrm{MPa}$ pressure. Magnification 1,000×; scale bar $=25 \mu \mathrm{m}$.

increases with increasing particle volume fraction, decreasing particle size, and increasing magnitude of interparticle forces (Poslinski et al., 1988; Genovese et al., 2007). Flow curves of the $5 \%$ fat samples (Figure 4) changed following aging, and a shift to higher stress values was observed. Analogously, apparent viscosity at $20 \mathrm{~s}^{-1}$ of $5 \%$ fat CON and CP mixes significantly increased after $20 \mathrm{~h}$ of aging (Table 2). This was expected because the hydration of proteins and stabilizers during aging causes a viscosity increase (Marshall and Arbuckle, 1996; Goff, 1997) possibly because of protein displacement from the surface back to the serum phase. No aging effect was observed in $5 \%$ fat HP mixes or in any of the $8 \%$ fat mixes. The latter had more surface area and hence, more adsorbed proteins, resulting in a faster stabilizing effect.

Apparent viscosities were lower for $\mathrm{CP}$ and higher for HP compared with CON for both $5 \%$ fat and $8 \%$ fat samples (Table 2). Schmidt and Smith (1989) observed a viscosity decrease in mixes homogenized at $\mathrm{CP}$ close to the values used in the present study. Those authors attributed the lowering of viscosity to changes in the size of the fat globules. With smaller fat globules, internal resistance is less than with larger ones or linear chains of globules. High-pressure homogenization caused a marked increase in the $\eta_{\text {app }}$ of mixes (Table 2 ), as was reported by Hayes et al. (2003), who attributed the viscosity increase to greater amounts of 

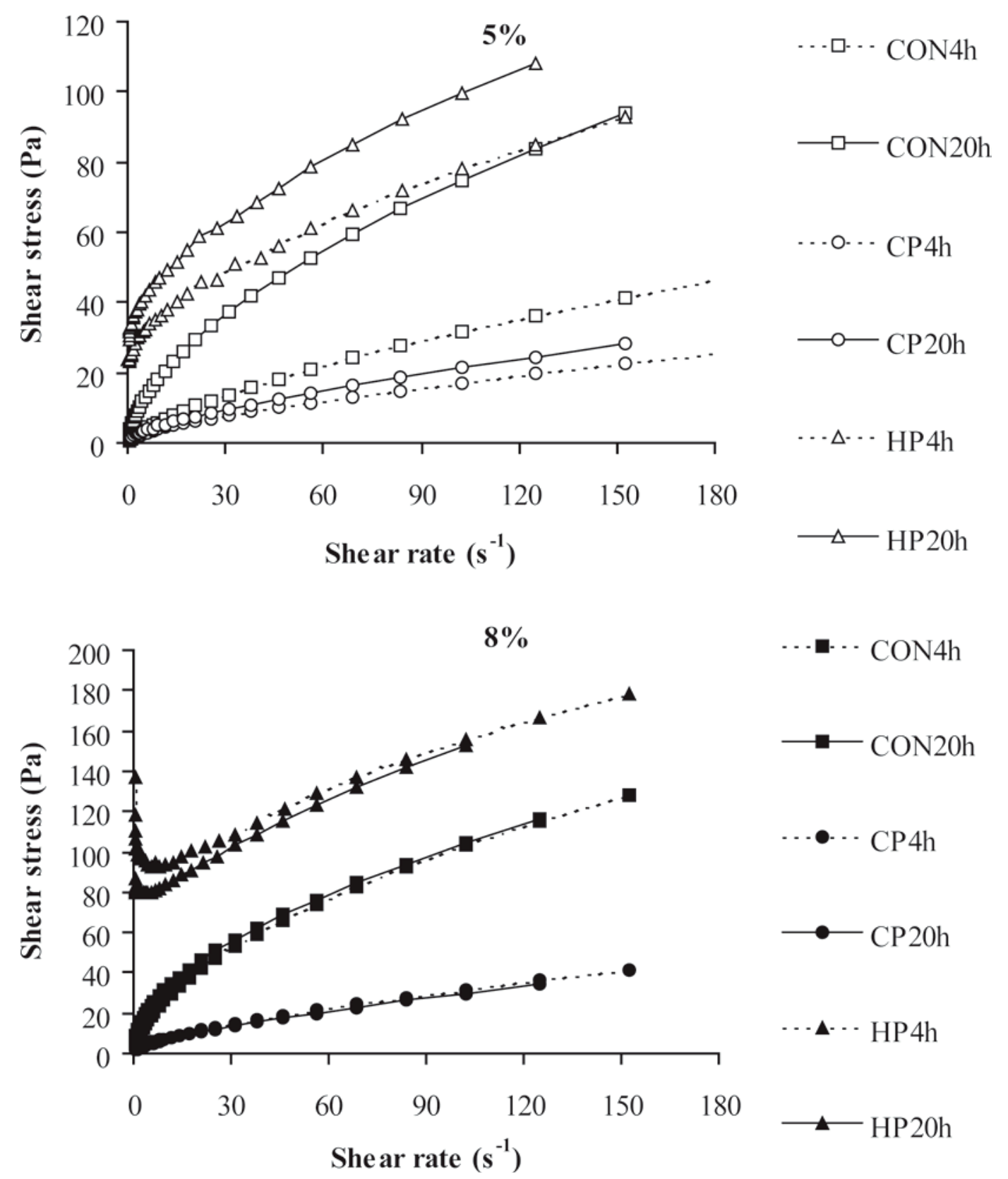

Figure 4. Representative steady shear flow curves of 5\% fat and $8 \%$ fat ice cream mixes aged for 4 and $20 \mathrm{~h}$. CON $=$ unhomogenized; CP $=$ homogenized at 15 and $3 \mathrm{MPa}$ pressure; $\mathrm{HP}=$ homogenized at 97 and $3 \mathrm{MPa}$ pressure.

absorbed proteins or more tightly packed proteins at the oil-water interface. Viscosity changes after processing were more pronounced in high fat content samples, which also had a higher initial $\eta_{\text {app }}$. Similarly, Hayes et al. (2003) reported higher viscosities for the $8 \%$ fat HP and CP mixes compared with the 5\% fat mixes. They also reported comparable viscosities for $5 \%$ fat $\mathrm{HP}$ and $8 \%$ fat $\mathrm{CP}$ ice cream mixes. In the present case, the viscosity of the $5 \%$ fat HP mix was comparable to that of the $8 \%$ fat $\mathrm{CON}$ mix. This difference can be attributed to the mix formulations used in the present study, which differed from those of Hayes et al. (2003) mainly because of a greater amount of stabilizers and emulsifiers.

\section{Dynamic Properties}

Mechanical spectra were performed in the frequency range 0.1 to $10 \mathrm{~Hz}$, at shear stresses within the linear viscoelastic region (previously determined by frequency 


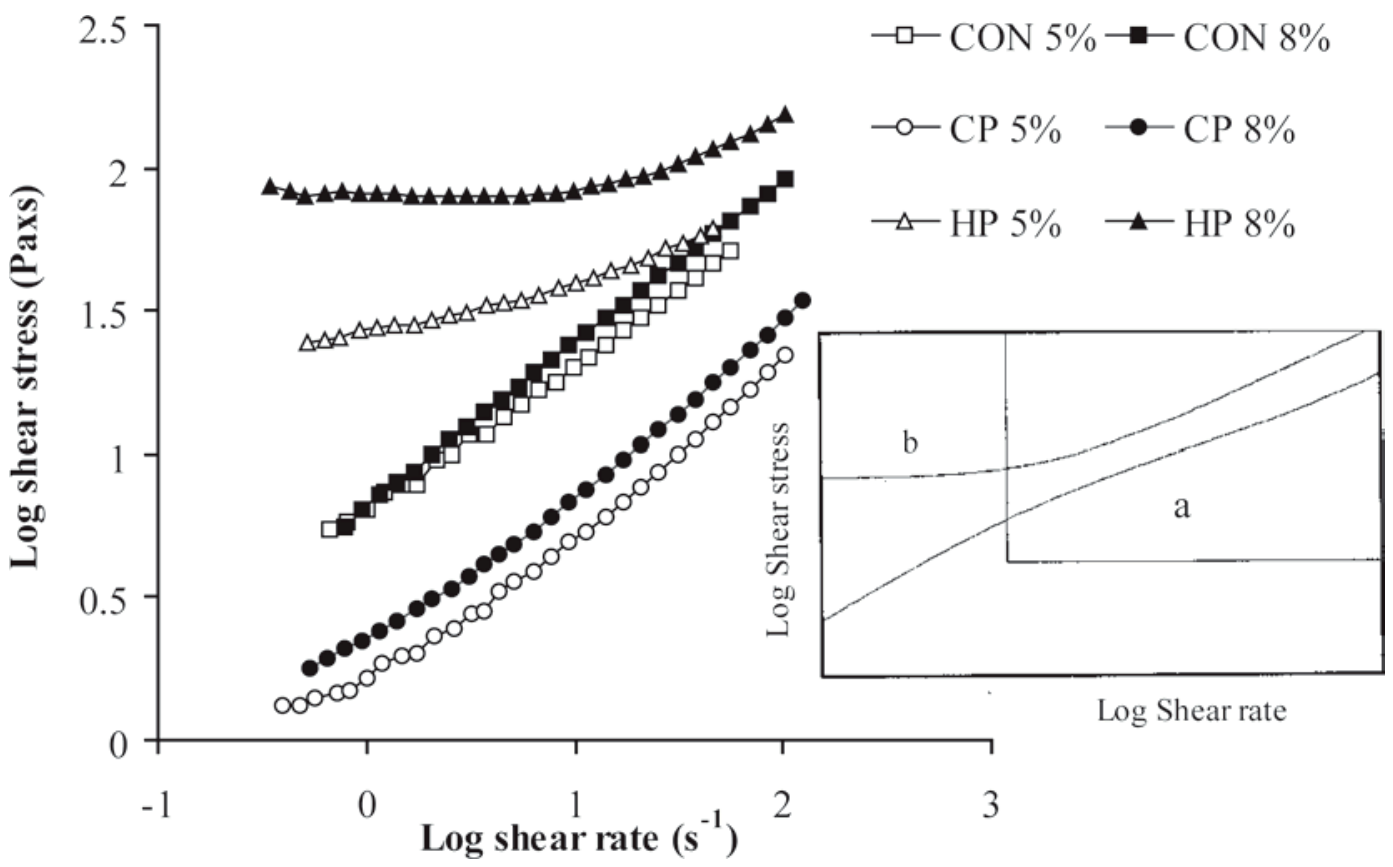

Figure 5. Logarithmic plot of shear stress versus shear rate of ice cream mixes. CON $=$ unhomogenized; CP $=$ homogenized at 15 and 3 $\mathrm{MPa}$ pressure; $\mathrm{HP}=$ homogenized at 97 and $3 \mathrm{MPa}$ pressure. Inner rectangle: Theoretical shear thinning (a) and plastic (b) behaviors reported in Lapasin and Pricl (1995).

stress sweeps). Linear viscoelastic ranges were seen to be wider and at higher stress values for HP-treated samples (data not shown). Critical deformations; that is, the maximum strain characterizing the limit of the linear viscoelastic regimen, were always less than approximately $6 \%$. In the literature, linear viscoelastic strain is reported to extend to approximately $20 \%$ for strong gels, whereas for weak gels it is usually $<5 \%$, but can be very much smaller (up to 1,000 times smaller; Ross-Murphy, 1995). An investigation of gel properties was performed by means of oscillatory measurements at a constant stress in the frequency range 0.1 to $10 \mathrm{~Hz}$. Figure 6 shows a representative mechanical spectrum of an HP mix in which the elastic modulus $\left(\mathbf{G}^{\prime}\right)$ is always higher than the viscous modulus $\left(\mathbf{G}^{\prime \prime}\right)$ and both are slightly frequency dependent; the phase angle is within 20 to $30^{\circ}$ and also slightly frequency dependent; complex viscosity decreases with increasing frequency. Systems with these characteristics are referred to as weak gels (Lapasin and Pricl, 1995; Ross-Murphy, 1995). Similar trends, which can be mainly attributed to the colloidal phase, were obtained for all samples, including the CON mixes. Viscoelastic properties may arise from pasteurization, which causes some protein denaturation and contributes to gel formation.

Although all samples exhibited gel-like properties, differences in the absolute value (compared at $1 \mathrm{~Hz}$ ) of dynamic moduli were observed. Figure 7 shows the

Table 2. Mean values and standard deviations of apparent viscosity (Pa.s; shear rate: $20 \mathrm{~s}^{-1}$ ) of $5 \%$ fat and $8 \%$ fat ice cream mixes subjected or not to homogenization and aged for 4 and $20 \mathrm{~h}$

\begin{tabular}{|c|c|c|c|c|}
\hline \multirow[b]{2}{*}{ Ice cream mix ${ }^{1}$} & \multicolumn{2}{|c|}{$5 \%$ fat } & \multicolumn{2}{|c|}{$8 \%$ fat } \\
\hline & $4 \mathrm{~h}$ & $20 \mathrm{~h}$ & $4 \mathrm{~h}$ & $20 \mathrm{~h}$ \\
\hline $\mathrm{CON}$ & $0.85^{\mathrm{ab}} \pm 0.67^{*}$ & $1.44^{\mathrm{b}} \pm 0.05^{*}$ & $2.07^{\mathrm{b}} \pm 0.06$ & $2.06^{\mathrm{b}} \pm 0.32$ \\
\hline $\mathrm{CP}$ & $0.31^{b} \pm 0.07^{*}$ & $0.40^{\mathrm{c}} \pm 0.03^{*}$ & $0.53^{\mathrm{c}} \pm 0.05$ & $0.52^{\mathrm{c}} \pm 0.01$ \\
\hline $\mathrm{HP}$ & $1.85^{\mathrm{a}} \pm 0.79$ & $2.28^{\mathrm{a}} \pm 0.55$ & $4.70^{\mathrm{a}} \pm 0.72$ & $4.57^{\mathrm{a}} \pm 0.18$ \\
\hline
\end{tabular}

${ }^{\mathrm{a}-\mathrm{c}}$ Different letters within the same column refer to statistical differences (Tukey's HSD test, $P<0.05$ ).

${ }^{1} \mathrm{CON}($ control $)=$ unhomogenized mix; $\mathrm{CP}($ conventional pressure $)=\operatorname{mix}$ homogenized at 15 and $3 \mathrm{MPa}$; $\mathrm{HP}$ $($ high pressure $)=\operatorname{mix}$ homogenized at 97 and $3 \mathrm{MPa}$.

*Within the same row, asterisks indicate statistical differences between 4 and $20 \mathrm{~h}$ aging time (Student's t-test, $P<0.05)$ 


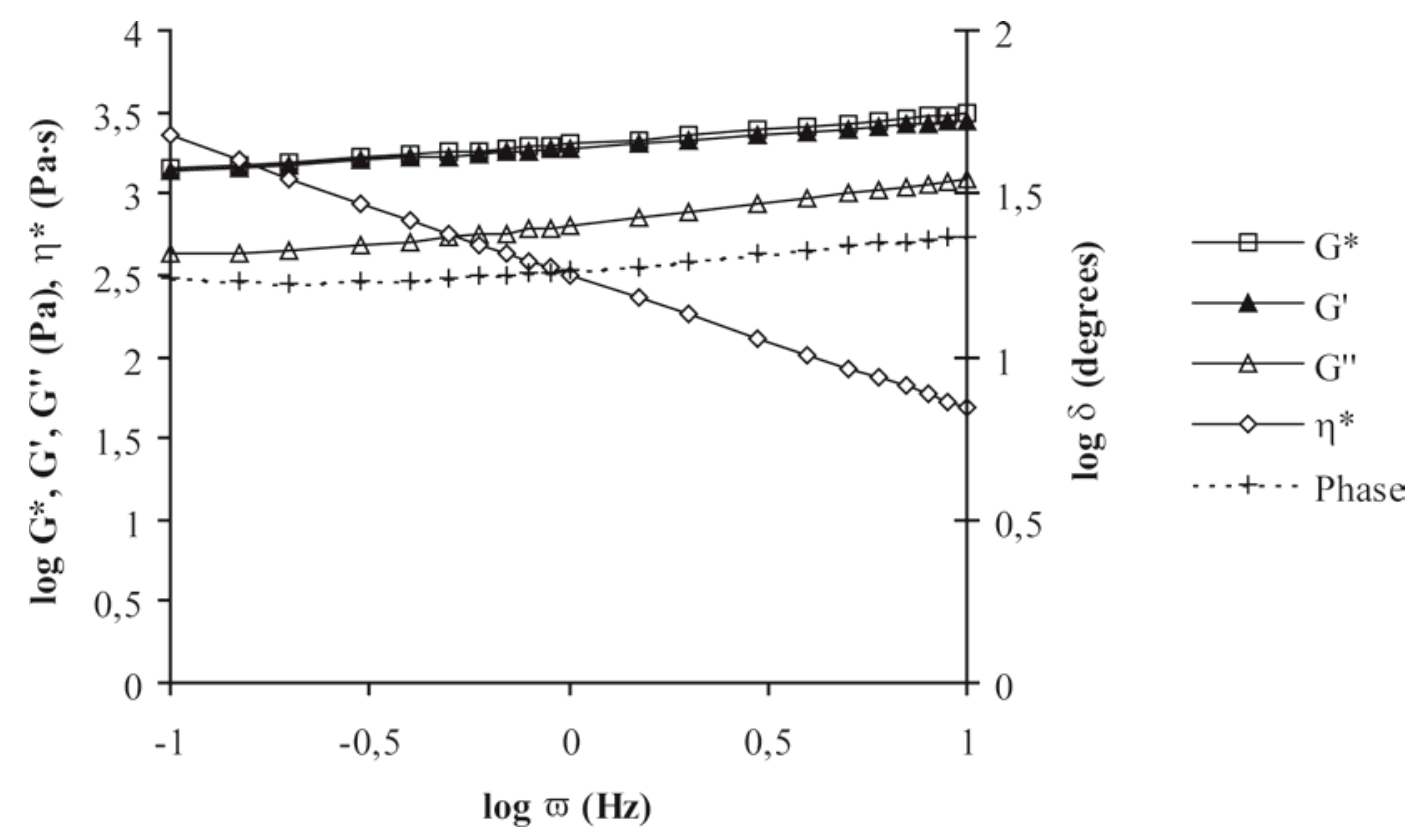

Figure 6. Representative mechanical spectrum of an HP (high-pressure) mix (homogenized at 97 and $3 \mathrm{MPa}$ ).

mean values and the standard deviations of complex moduli $\left(\mathbf{G}^{*}\right)$ of $\mathrm{CON}, \mathrm{CP}$, and HP ice cream mixes at 5 and $8 \%$ fat content aged for 4 and $20 \mathrm{~h}$. The complex modulus $\mathrm{G}^{*}$ was chosen as an indication of the system strength; $\mathrm{G}^{*}$ of $5 \%$ fat $\mathrm{CP}$ mixes was the lowest and $\mathrm{G}^{*}$ of HP $8 \%$ fat the highest. All $5 \%$ fat mixes showed a $\mathrm{G}^{*}$ increase at $20 \mathrm{~h}$ compared with $4 \mathrm{~h}$. Conversely, in the $8 \%$ fat samples, $\mathrm{G}^{*}$ was almost constant suggesting that higher fat contents had a stabilizing effect on the viscoelastic properties of mixes, as was also observed for apparent viscosity (Table 2). The HP samples, both
5 and $8 \%$ fat, showed higher $\mathrm{G}^{*}$. As described above, ice cream mixes may be considered as emulsion-filled gels. The elastic modulus $\mathrm{G}^{\prime}$ in HP mixes markedly increased from $258 \mathrm{~Pa}$ in $5 \%$ fat mixes to $1,804 \mathrm{~Pa}$ in $8 \%$ fat mixes; therefore it can be inferred that, in these systems, fat behaves as an interactive filler. This may arise from HP treatment, because $\mathrm{CP}$ and $\mathrm{CON}$ did not show an increase in $\mathrm{G}^{\prime}$.

Another useful parameter to characterize a viscoelastic system is the ratio $\mathrm{G}^{\prime \prime}: \mathrm{G}^{\prime}$, named loss tangent (tan $\delta)$, which is a measure of the viscous/elastic ratio for a

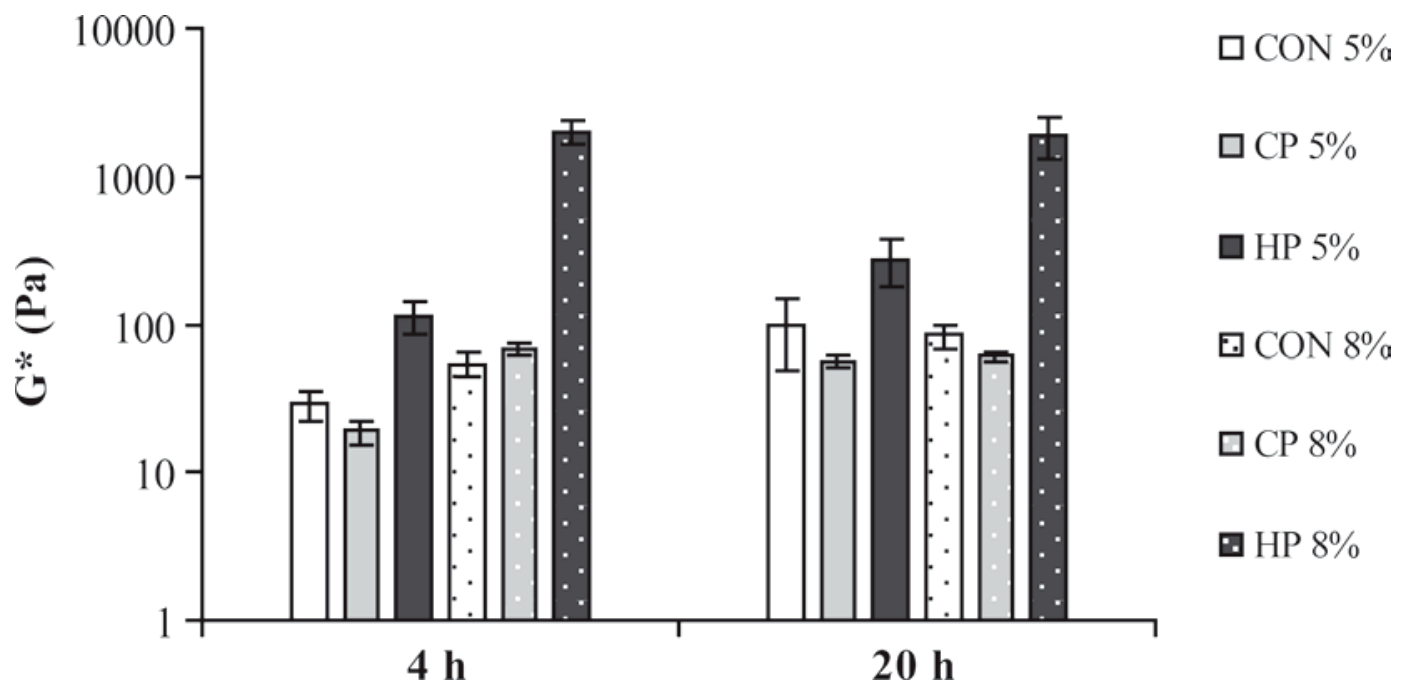

Figure 7. Mean values and standard deviations of complex modulus of ice cream mixes at $5 \%$ and $8 \%$ fat content aged for 4 and 20 h. CON $=$ unhomogenized; $\mathrm{CP}=$ homogenized at 15 and $3 \mathrm{MPa}$ pressure; $\mathrm{HP}=$ homogenized at 97 and $3 \mathrm{MPa}$ pressure. 
Table 3. Mean values and standard deviations of calculated $\tan \delta$ of ice cream mixes at $5 \%$ and $8 \%$ fat content aged for 4 and $20 \mathrm{~h}$

\begin{tabular}{lccccc}
\hline & \multicolumn{2}{c}{$5 \%$ fat } & & \multicolumn{2}{c}{$8 \%$ fat } \\
\cline { 2 - 3 } \cline { 5 - 6 } Ice cream mix $^{1}$ & $4 \mathrm{~h}$ & $20 \mathrm{~h}$ & & $4 \mathrm{~h}$ & $20 \mathrm{~h}$ \\
\hline $\mathrm{CON}$ & $0.70 \pm 0.08$ & $0.57 \pm 0.02$ & & $0.66 \pm 0.09$ & $0.54 \pm 0.04$ \\
$\mathrm{CP}$ & $0.72 \pm 0.02$ & $0.53 \pm 0.03$ & & $0.55 \pm 0.02$ & $0.53 \pm 0.02$ \\
$\mathrm{HP}$ & $0.38 \pm 0.03$ & $0.36 \pm 0.04$ & & $0.33 \pm 0.01$ & $0.35 \pm 0.02$ \\
\hline
\end{tabular}

${ }^{1} \mathrm{CON}($ control $)=$ unhomogenized mix; $\mathrm{CP}($ conventional pressure $)=$ mix homogenized at 15 and $3 \mathrm{MPa}$;P (high pressure $)=\operatorname{mix}$ homogenized at 97 and $3 \mathrm{MPa}$.

material at frequency $\omega$ (Ross-Murphy, 1995). The loss tangent curve did not show variations over the frequency range 0.1 to $10 \mathrm{~Hz}$ (data not shown). Values of $\tan \delta$ at $1 \mathrm{~Hz}$ frequency are compared in Table 3. Both 5 and $8 \%$ fat $\mathrm{HP}$ mixes showed tan $\delta$ lower than those of $\mathrm{CP}$ and CON, indicating a more structured gel-like system. The HP homogenization would give structure to the system and strengthen the elastic component, possibly as a consequence of pressure-induced colloidal interactions and network formation. The Cox-Merz superposition rule constitutes a further criterion for the distinction between gel systems and biopolymer entangled solutions, by combining oscillatory and steady shear measurements. In the Cox-Merz superposition the curves of $\eta$ versus shear rate and $\eta^{*}$ versus $\omega$ are plotted on the same diagram. The results, reported in Figure 8, show that in all cases the curves are not superposed, which is typical of colloidal and particulate gel networks (RossMurphy, 1995). In CON samples, the curves tend to cross with increasing shear rate and frequency, whereas in CP mixes, this tendency was less clear. In HP mixes the 2 curves were in parallel. The convergence of the 2 curves refers to weak gels, whereas the parallelism is typical of strong gels (Ross-Murphy, 1995). According to these data, CON and CP mixes behaved as weak gels and HP samples as stronger gels. High-pressure homogenization on a model oil-in-water emulsion was used by Floury et al. (2000) and they related the effect of HP homogenization not only to the change in emulsion droplet size but also to the properties of the stabilizer molecules. The authors hypothesized an unfolding or partial denaturation of the globular proteins caused by treatments at high pressure and simultaneously high temperature. A similar mechanism may be suggested to explain the HP structuring effect on the ice cream mixes; that is, the HP treatment could cause the unfolding or partial denaturation of both whey protein and caseins leading to a network formation or rearrangement or to interpenetrating networks within the colloidal phase. In contrast, $\mathrm{CP}$ pressures would not enable changes at such extents. Similarly, Floury et al. (2002) reported a strong gel-type behavior for soy protein-stabilized emulsions when homogenized at UHP (250 and 350 $\mathrm{MPa}$ ). The authors suggested that disulfide bonding and noncovalent bonds such as hydrophobic interaction and ionic and hydrogen bonding may be involved in the gel-like formation when produced at homogenizing pressures $>200 \mathrm{MPa}$.

\section{CONCLUSIONS}

Homogenization of ice cream mixes resulted in a change from bimodal to monomodal particle size distributions with a progressive reduction in the mean particle diameter as pressure increased from conventional to high values. Because the milk and milk cream used as ingredients in mix formulation were already conventionally homogenized, the further modification in the particle sizes and distributions following the $\mathrm{CP}$ process of the mixes could be attributed to the effects of the increased viscosity of ice cream mixes. Fat globule mean diameters were reduced at higher pressure, but the homogenization effect on size reduction was limited with the highest fat content.

The rheological behavior of ice cream mixes was determined by both the dispersed and the continuous phase. In most cases, the dispersed phase accounted mainly for viscosity, whereas the colloidal phase was responsible for the viscoelastic properties and gel behavior. Higher fat contents resulted in both higher viscosity and dynamic moduli. Homogenization at $\mathrm{CP}$ mainly affected the dispersed phase and determined a more pronounced viscosity reduction in the higher fat content mixes. This effect was related to fat globule size reduction, whereas the viscoelastic properties were only slightly influenced by the process. Homogenization at HP caused a further slight decrease in particle size with respect to $\mathrm{CP}$, but a strong enhancement of the viscoelastic properties and apparent viscosity. Hence, the HP treatment acted mainly on the colloidal phase.

Rheological results indicated that unhomogenized and CP mixes behaved as weak gels, whereas HP treatment led to stronger gels possibly as the overall result of a network rearrangement or interpenetrating network 

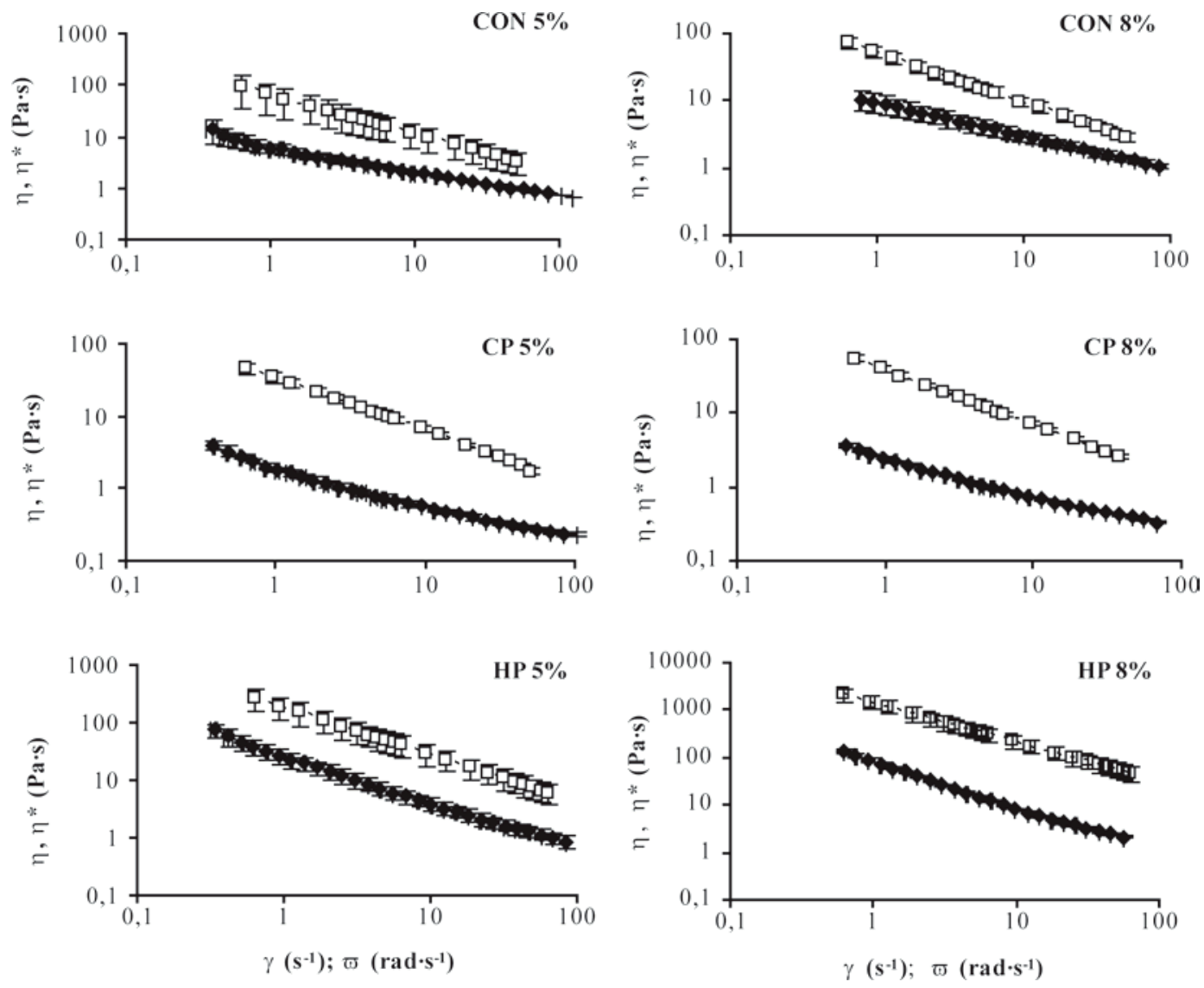

Figure 8. Cox-Merz superposition of steady shear flow viscosity $(\eta)$ versus shear rate $(\gamma, \boldsymbol{\square})$ and complex viscosity $\left(\eta^{*}\right)$ versus frequency $(\omega$, $\square$ ) for samples at $5 \%$ fat (left column) and $8 \%$ fat (right column) aged for $20 \mathrm{~h}$.

formation and the fat globules were found to behave as active filler. It should be noted that the HP process produced an apparent viscosity in the $5 \%$ fat mix comparable to that of the $8 \%$ fat CON mix. Further research needs to be undertaken to determine whether HP homogenization of ice cream mixes could enable the production of lower fat ice creams with similar characteristics to those of higher fat ice creams.

\section{ACKNOWLEDGMENTS}

The authors are grateful to Enrico Maltini (Department of Food Science, University of Udine) for his helpful advice.

\section{REFERENCES}

Aguilera, J. M., and D. W. Stanley. 1999. Microstructural principles of food processing and engineering. 2nd ed. Aspen Publishers Inc., Gaithersburg, MD.

Alvarez, V. B., C. L. Wolters, Y. Vodovotz, and T. Ji. 2005. Physical properties of ice cream containing milk protein concentrates. J. Dairy Sci. 88:862-871.
Bouaouina, H., A. Desrumaux, C. Loisel, and J. Legrand. 2006. Functional properties of whey proteins as affected by dynamic high-pressure treatment. Int. Dairy J. 16:275-284.

Cottrell, J. I. L., G. Pass, and G. O. Phillips. 1980. The effect of stabilizers on the viscosity of an ice cream mix. J. Sci. Food Agric. 31:1066-1070

Desrumaux, A., and J. Marcand. 2002. Formation of sunflower oil emulsions stabilized by whey proteins with high-pressure homogenization (up to $350 \mathrm{MPa}$ ): Effect of pressure on emulsion characteristics. Int. J. Food Sci. Technol. 37:263-269.

Fellows, P. 1988. Food Processing Technology. Principles and Practice. Ellis Horwood Ltd., Chichester, UK.

Floury, J., A. Desrumaux, M. A. V. Axelos, and J. Legrand. 2003 Effect of high pressure homogenisation on methylcellulose as food emulsifier. J. Food Eng. 58:227-238.

Floury, J., A. Desrumaux, and J. Lardières. 2000. Effect of highpressure homogenization on droplet size distributions and rheological properties of model oil-in-water emulsions. Innov. Food Sci. Emerg. 1:127-134.

Floury, J., A. Desrumaux, and J. Legrand. 2002. Effect of ultra-highpressure homogenization on structure and on rheological properties of soy protein-stabilized emulsions. J. Food Sci. 67:3388-3395.

García-Risco, M. R., M. Ramos, and R. López-Fandiño. 2002 Modifications in milk proteins induced by heat treatment and homogenization and their influence on susceptibility to proteolysis. Int. Dairy J. 12:679-688.

Gelin, J. L., L. Poyen, J. L. Courthaudon, M. Le Meste, and D. Lorient. 1994. Structural changes in oil-in-water emulsions during the manufacture of ice cream. Food Hydrocolloids 3/4:299-308. 
Genovese, D. B., J. E. Lozano, and M. A. Rao. 2007. The rheology of colloidal and noncolloidal food dispersions. J. Food Sci. 72:1120.

Goff, H. D. 1997. Colloidal aspects of ice cream-A review. Int. Dairy J. $7: 363-373$.

Goff, H. D. 2002. Formation and stabilisation of structure in ice-cream and related products. Curr. Opin. Colloid. Interface Sci. 7:432437.

Goff, H. D., V. J. Davidson, and E. Cappi. 1994. Viscosity of ice cream mix at pasteurization temperatures. J. Dairy Sci. 77:2207-2213.

Goff, H. D., E. Verespej, and A. K. Smith. 1999. A study of fat and ice structures in ice cream. Int. Dairy J. 9:817-829.

Hayes, M. G., and A. L. Kelly. 2003. High pressure homogenisation of raw whole bovine milk (a) effects on fat globule size and other properties. J. Dairy Res. 70:297-305.

Hayes, M. G., A. C. Lefrancois, D. S. Waldron, H. D. Goff, and A. L. Kelly. 2003. Influence of high pressure homogenization on some characteristics of ice cream. Milchwissenschaft 58:519-523.

Kessler, H. G. 1981. Food Engineering and Dairy Technology. Verlag A. Kessler, Freising, Germany.

Koxholt, M. M. R., B. Eisenmann, and J. Hinrichs. 2001. Effect of fat globule sizes on the meltdown of ice cream. J. Dairy Sci. $84: 31-37$.

Lapasin, R., and S. Pricl. 1995. Rheology of industrial polysaccharides. Theory and application. Blackie Academic \& Professional, Glasgow, UK.

Marshall, R. T., and W. S. Arbuckle. 1996. Ice Cream. 5th ed. Chapman and Hall, New York, NY.

Muse, M. R., and R. W. Hartel. 2004. Ice cream structural elements that affect melting rate and hardness. J. Dairy Sci. 87:1-10.

Paquin, P. 1999. Technological properties of high pressure homogenizers: the effect of fat globules, milk proteins and polysaccharides. Int. Dairy J. 9:329-335.
Phipps, L. W. 1975. The fragmentation of oil drops in emulsions by high-pressure homogenizer. J. Phys. D Appl. Phys. 8:448-462.

Poslinski, A. J., M. E. Ryan, R. K. Gupta, S. G. Seshadri, and F. J. Frechette. 1988. Rheological behaviour of filled polymeric systems. I. Yield stress and shear thinning effects. J. Rheol. (N.Y.N.Y.) $32: 703-735$.

Rao, M. A. 2007. Rheology of fluid and semisolid foods. Principles and applications. 2nd ed. Springer, New York, NY.

Roach, A., and F. Harte. 2008. Disruption and sedimentation of casein micelles and casein micelle isolates under high-pressure homogenization. Innov. Food Sci. Emerg. 9:1-8.

Ross-Murphy, S. B. 1995. Rheology of biopolymer solutions and gels. Pages 139-156 in New Physico-Chemical Techniques for the Characterization of Complex Food Systems. E. Dickinson ed. Blackie Academic \& Professional, Glasgow, UK.

Sandra, S., and D. G. Dalgleish. 2005. Effects of ultra-high-pressure homogenization and heating on structural properties of casein micelles in reconstituted skim milk powder. Int. Dairy J. 15:10951104 .

Schmidt, K. A., and D. E. Smith. 1988. Effects of homogenization on sensory characteristics of vanilla ice cream. J. Dairy Sci. 71:4651.

Schmidt, K. A., and D. E. Smith. 1989. Effects of varying homogenization pressure on the physical properties of vanilla ice cream. J. Dairy Sci. $72: 378-384$.

Subirade, M., F. Loupil, A.-F. Allain, and P. Paquin. 1998. Effect of dynamic high pressure on the secondary structure of $\beta$-lactoglobulin and on its conformational properties as determined by Fourier transform infrared spectroscopy. Int. Dairy J. 8:135-140.

Tolstoguzov, V. 2003. Some thermodynamic considerations in food formulation. Food Hydrocolloids 17:1-23.

van Vliet, T. 1988. Rheological properties of filled gels. Influence of filler matrix interaction. Colloid Polym. Sci. 266:518-524. 